\title{
KAJIAN AWAL PENGEMBANGAN PRODUK DENGAN MENGGUNAKAN METODE QFD (QUALITY FUNCTION DEPLOYMENT) (STUDI KASUS PADA TANG JEPIT JAW LOCKING PLIERS)
}

\author{
K. Rihendra Dantes \\ Jurusan Pendidikan Teknik Mesin, Fakultas Teknik dan Kejuruan \\ Universitas Pendidikan Ganesha \\ Singaraja, Indonesia \\ email: rihendra dantes@yahoo.co.id
}

\begin{abstract}
Abstrak
Penelitian ini bertujuan untuk mengkaji indikator-indikator yang menjadi hal penting dalam pengembangan sebuah produk otomotif tang jepit "Jaw Locking Pliers". Pengemabngan produk ini dilakukan dengan menggunakan metode QFD (Quality Function Deployment) yaitu suatu metode yang terstruktur di dalam pengembangan produk yang memungkinkan tim pengembangan produk untuk menetapkan dengan jelas semua keinginan dan kebutuhan konsumen dan kemudian mengevaluasi masing-masing kemampuan produk atau service yang ditawarkan secara sistematis untuk memenuhi kebutuhan konsumen. Permintaan customer (customer needs) merupakan masukan utama QFD, sedang langkah prosesnya ada 4 fase dimana Dari urutan fase QFD, product planning (penyusunan House of Quality) merupakan fase pertama dan bertujuan untuk mendapatkan nilai prioritas masing-masing Substitute Quality Characteristics (SQC) yang nantinya akan menjadi masukan pada tahapan Parts Deployment.
\end{abstract}

Kata Kunci: QFD (Quality Function Deployment), HOQ (House of Quality), SQC (Substitute Quality Characteristics), Tang Jepit "Jaw Locking Pliers"

\begin{abstract}
The study aimed to assess indicators that become the prominent factor in developing an automotive product, in which the product being developed is clamo pliers "jaw locking pliers". The development of this product done through QFD (quality function deployment), a structured method in developing the product that enable the product development team to determine clearly all desires and needs of the customer and then evaluate each product as well as service affered systematically to meet the needs of the customer. Customer demand is the main input of QFD, in which the are four stepsof QFD phase, the first step is product planning (preparation of the house of quality), which the aim is to get the priority value of each substitute quality characteristics (SQC) that will become input fore the part deployment step.
\end{abstract}

Keyword: QFD (Quality Function Deployment), HOQ (House of Quality), SQC (Substitute Quality Characteristics), Jaw Locking Pliers 


\section{PENDAHULUAN}

Persyaratan rancangan suatu produk adalah rancangan yang dapat dirakit, dapat didaur ulang, bebas dari korosi atau karat, biaya yang rendah dan dapat dimanufaktur serta dapat diperiksa hasil akhirnya. Kualitas suatu produk merupakan salah satu faktor penting dalam meningkatkan daya saing produk, selain biaya produksi dan ketepatan waktu produksi.

Pada perancangan produk ini akan dikembangkan produk Tang Jepit (Jaw Locking Pliers). Pada umumnya alat ini sering digunakan pada dunia perbengkelan. Alat ini berfungsi sebagai alat penjepit baut, mur, atau benda kerja yang lain agar benda yang dijepit tidak mudah berputar atau bergeser dari tempat semula atau dari tempat yang diharapkan.

Alasan peneliti

tertarik mengembangkan produk ini berdasarkan study pendahuluan yang dilakukan peneliti dimana banyak pemakai alat ini mengalami kesulitan dalam menggunakan dengan alasan yang bervariasi, tetapi kesulitan yang timbul tidak mempengaruhi atau mengurangi mobilitas penggunaan alat ini oleh pengguna dilihat dari pentingnya kegunaan alat ini. Sehingga berdasarkan hal diatas maka penulis berinisiatif untuk mengembangkan produk Jaw Locking Pliers atau yang sering dikenal "Tang Jepit".

Sebuah Tang Jepit (Jaw Locking Pliers) akan dikembangkan sesuai dengan perkembangan teknologi dan atas permintaan pengguna (customer), berdasarkan atas spesifikasi teknis dan permintaan tersebut akan diwujudkan dengan konsep yang akan dapat mengarahkan kualitas produk. Guna mendapatkan informasi tentang kebutuhan customer akan dilakukan :

1. Tanya jawab langsung kepada customer

2. Menyebarkan kuisioner kepada customer

3. Mempelajari dan mengembangkan produk yang sudah ada.
Untuk mengetahui suara customer (customer needs) dengen menyebarkan kuisioner pengembangan produk Tang jepit "Jaw Locking Pliers" ke konsumen

Penelian ini bertujuan antara lain:

- Menerapkan QFD kedalam proses perancangan dan pengembangan produk.

- Untuk mengetahui seberapa besar kontribusi QFD dalam proses perancangan dan pengembangan produk.

- Mempelajari bagaimana proses perancangan yang melibatkan customer, sehingga hasil dari proses perancangan tersebut benar-benar menjawab kebutuhan pasar (customer).

QFD adalah suatu metode yang terstruktur didalam pengembangan produk yang memungkinkan tim pengembangan produk untuk menetapkan dengan jelas semua keinginan dan kebutuhan konsumen dan kemudian mengevaluasi masing-masing kemampuan produk atau servis yang ditawarkan secara sistematis untuk memenuhi kebutuhan konsumen [Cohen 95].

QFD merupakan suatu praktek untuk mengembangkan produk sebagai tanggapan terhadap kebutuhan pelanggan menjadi apa yang dihasilkan perusahaan dengan cara memberi prioritas dan juga merupakan praktek menuju perbaikan proses yang memungkinkan perusahaan melampoi harapan pelanggan [UIIman].

QFD adalah suatu alat dalam perencanaan yang dipergunakan untuk memenuhi keinginan pelanggan. [Besterfield.et.al, 1995].

Jadi QFD merupakan metode atau alat bantu, guna melakukan perancangan dan pengembangan produk yang terstruktur, yang memungkinkan tim pengembangan produk dapat mengidentifikasikan keinginan dan kebutuhan customer dengan jelas, kemudian mengevaluasi masing-masing kemampuan produk atau kemampuan 
pelayanan yang ditawarkan secara sistematis guna memenuhi kebutuhan customer.

Permintaan customer (customer needs) merupakan masukan utama QFD, sedang langkah prosesnya ada 4 fase yang dapat dilihat pada gambar 1 dibawah ini.

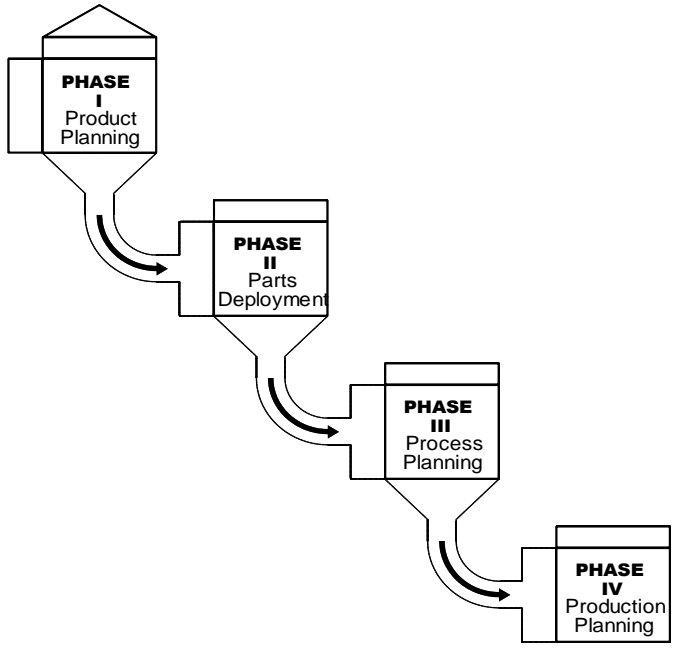

Gambar 1. Phase QFD [Liu,Kliewer, Stephen,Weening]

Adapun beberapa manfaat yang didapatkan dengan menerapkan $Q F D$ adalah :

1. Memusatkan perancangan produk dan jasa baru pada kebutuhan pelanggan.

2. Memastikan kebutuhan pelanggan dipahami dan mendorong proses desain.

3. Mengutamakan kegiatan desain, memastikan proses desain dipusatkan pada kebutuhan konsumen yang paling berarti.

4. Menganalisa kinerja produk perusahaan terhadap kinerja pesaing-pesaing perusahaan yang utama untuk memenuhi kebutuhan utama pelanggan.

5. Berfokus pada upaya perancangan sehingga meminimalkan waktu perancangan secara keseluruhan. Pemikiran baru memperhatikan adanya penghematan 1/4 sampai 1/3 dibanding sebelum QFD dilakukan.
6. Mengurangi pengubahan desain setelah dikeluarkan dengan memastikan upaya yang berfokus pada tahap perencanaan.

Dari urutan fase $Q F D$, product planning (penyusunan House of Quality) merupakan fase pertama dan bertujuan untuk mendapatkan nilai prioritas masing-masing Substitute Quality Characteristics (SQC) yang nantinya akan menjadi masukan pada tahapan Parts Deployment.

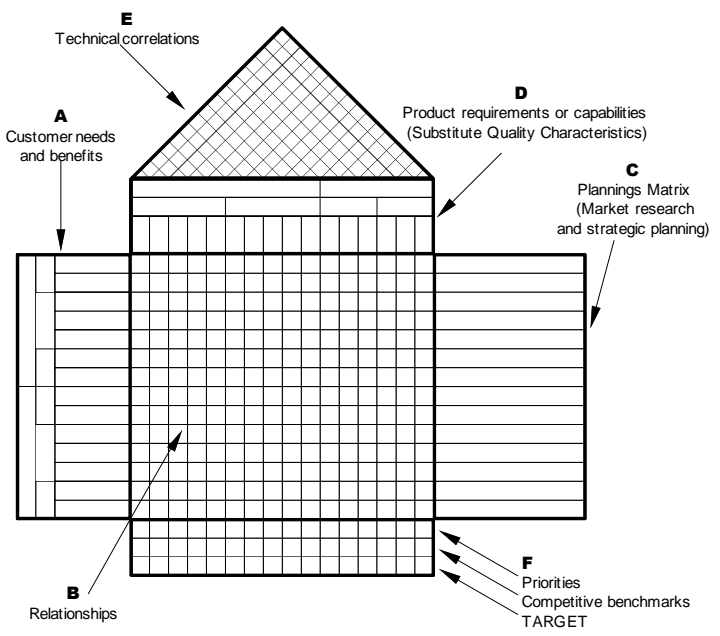

Gambar 2. HOQ (HoseOf Quality)

Keterangan :

> Bagian A : berisi data/informasi yang diperoleh dari penelitian pasar tentang kebutuhan dan keinginan konsumen

$>$ Bagian B : Berisi 3 jenis data yaitu :

1. Data pasar kuantitatif, yang menunjukkan tentang kepentingan relatif dari customer needs and benefits, dan tingkat kepuasan customer terhadap kompetisi tawaran saat ini dan organisasi.

2. Penetapan tujuan strategis untuk pelayanan dan produk baru.

3. Perhitungan untuk urutan prioritas dari keinginan dan kebutuhan customer.

Bagian C : Berisi persyaratan teknis untuk produk jasa baru yang akan dikembangkan. Data diturunkan berdasarkan informasi yang diperoleh Jurnal Sains dan Teknologi| 175 
mengenai kebutuhan dan keinginan konsumen (Bagian: A)

$>$ Bagian D : Berisi penilaian menejemen mengenai kekuatan hubungan antara elemen-elemen yang terdapat pada (technical respon) persyaratan teknis (Bagian: C) terhadap (customer needs) keinginan konsumen (Bagian: A).

$>$ Bagian E : Menunjukkan korelasi antara persyaratan teknis yang satu dengan yang lain yeng terdapat di Bagian: $\mathrm{C}$.

$>$ Bagian $\mathbf{F}$ : Berisi 3 jenis data yaitu :

1. Urutan tingkat kepentingan (prioritas) persyaratan teknis didasarkan pada urutan customer needs dan urutan keinginan dari Bagian: B dan hubungannya pada Bagian: D

2. Informasi hasil perbandingan kinerja teknis produk/jasa yang dihasilkan oleh perusahaan terhadap kinerja produk pesaing

3. Target kinerja persyaratan teknis produk atau jasa yang baru dikembangkan.

\section{METODE}

Quality Function Deployment (QFD) merupakan suatu metode yang dipakai dalam tahap awal perancangan dan pengembangan produk dimana membuat rancangan kualitas dari suatu produk berdasarkan atas permintaan kualitas dari pemesanan (Customer) atau pasar (Market). QFD merupakan metode yang digunakan untuk mengantisipasi dan menentukan prioritas kebutuhan dan keinginan konsumen, serta menggabungkan kebutuhan dan keinginan konsumen tersebut dalam produk barang maupun jasa yang dihasilkan perusahaan.

Dalam proses perancangan dan pengembangan produk diperlukan suatu proses pencarian data tentang apa saja yang menjadi tututan pasar. Untuk dapat memperoleh informasi dan kebutuhan customer diperlukan suatu metode untuk melakukannya. Metode yang umum dilakukan adalah:
1. Wawancara langsung dengan customer. 2. Kuisioner

Dengan memperhatikan keterbatasan waktu, maka pencarian informasi tentang keinginan dan kebutuhan customer dilakukan dengan metode kuisioner. Adapun customer yang dilibatkan adalah seluruh mekanik bengkel di kecamatan Buleleng.

Pengolahan data yang di dapatkan dari data kuisioner kemudian data dapat dirangkum untuk dijadikan dasar dalam membuat "Permintaan Kualitas Customer (PKC)" atau "Voice Of Customer (VOC)". Data dari customer ditabelkan dan dihitung perolehan jumlah kuisioner serta nilai total masing-masing pertanyaan. Tabel ini gunanya untuk mempermudah melihat angka perolehan skor atau prioritas pertanyaan pada kuisioner dari customer.

Lebih lanjut, langkah-langkah penelitian ini di uraikan sebagaia berikut:

\section{Konsep Pengembangan Produk}

Cara terbaik untuk membuat atau mewujudkan konsep suatu produk adalah mengembangkan sebuah teknik berdasarkan atas fungsi produk (system) atau komponen itu sendiri. Teknik ini akan membantu dalam pemecahan masalah dan memberikan kesempatan untuk mencari jalan keluar (solusi) yang kreatif. Untuk itu perlu memusatkan perhatian kita pada tehnik pemecahan fungsi produk (functional decoposition) dan variasi perwujudan konsep (concept variant generation). Hal ini didasarkan atas kenyataan bahwa banyak kebutuhan penting pelanggan yang harus dipenuhi. Pemenuhan fungsi produk (system) merupakan penilaian performasi dari produk itu sendiri.

Perancangan untuk manufaktur meliputi dua aktivitas penting yaitu perancangan dan pengembangan produk. Perancangan dan pengembangan produk harus dilakukan secara matang, karena proses ini akan menentukan proses selanjutnya. Adapun langkah-langkah yang harus dilakukan oleh seorang desainer dalam perancangan dan 
pengembangan produk adalah sebagai berikut:

1. Mengidentifikasi kebutuhan konsumen

2. Membuat spesifikasi produk

3. Menganalisa kompetensi produk di pasar

4. Pengembangan konsep

5. Pemilihan konsep

6. Penyempurnaan spesifikasi

7. Analisa secara ekonomi

8. Merencanakan proyek

Delapan tahapan tersebut dilakukan oleh beberapa yang tergabung dalam tim yang disebut dengan development tim. Tim tersebut biasanya meliputi bagian pemasaran (marketing), perancang (designer), produksi ( manufacture), mampu ukur, kontrol kulitas (quality control) dan masih banyak lagi.

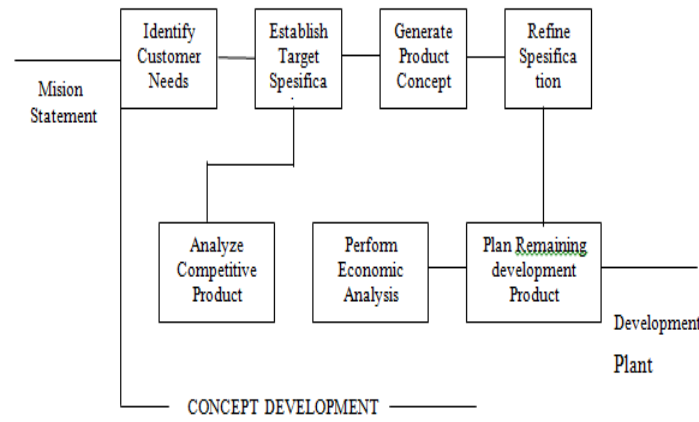

Gambar 3 Diagram Alir Pengembangan Konsep(Ulrich,1995)

\section{Mengidentifikasi Kebutuhan Konsumen}

Sesuai dengan kegiatan ini adalah untuk memahami kebutuhan konsumen dan mengkomunikasikan secara efektif kepada tim pengembang.

\section{Membuat Target Spesifikasi}

Spesifikasi adalah suatu gambaran secara jelas mengenai fungsi produk. Spesifikasi juga merupakan translasi dari yang dibutuhkan oleh konsumen ke dalam terminologis teknis.

\section{Analisa dari Kompetensi Produk}

Memahami spesifikasi yang sudah ada di pasaran, sehingga dari hal tersebut bisa dikembangkan suatu produk yang mempunyai keunggulan-keunggulan dari pada produk yang sudah ada di pasaran.

\section{Pengembangan konsep}

Sasaran dari pengembangan konsep suatu produk ini adalah untuk melihat lebih lanjut jauh apakah produk yang akan dibuat sudah memenuhi kebutuhan konsumen. Dalam pengembangan konsep ini masingmasing individu dari tim pengembang akan menawarkan konsep masing-masing yang masih dalam bentuk sket dan penjelasan yang sederhana.

\section{Pemilihan Konsep}

Konsep yang ditawarkan oleh individuindividu lain dari tim pengembang, selanjutnya diseleksi melalui metode screening dan metode scoring. Sehingga hasil dari screening dan scoring nantinya ada desain produk yang memenuhi kriteria konsumen, biaya murah, dapat diproses (manufacturability) dan dapat diperiksa.

\section{Penyempurnaan Spesifikasi}

Spesifikasi produk yang telah ditentukan sebelumnya akan ditinjau ulang kembali sebagai konsekuensi dari proses pemilihan konsep, karena biasanya konsep produk yang dihasilkan dari proses penyeleksian tidak murni hasil pemikiran dari suatu individu dalam tim pengembang, tetapi lebih merupakan gabungan dari masing-masing konsep yang ditawarkan individu-individu. Sehingga pada tahapan ini pengembang harus menetapkan kembali spesifikasi produk.

\section{Analisa Secara Ekonomi}

Tim pengembang dibantu oleh ahli ekonomi untuk membuat suatu model produk yang bernilai ekonomis. Di sini sudah dihitung biaya pengembangan dan pembuatan (manufacture) untuk jangka waktu tertentu. 


\section{Perencanaan Proyek}

Perencanaan proyek adalah tahapan terakhir dari metode perancangan dan pengembangan produk. Pada tahapan ini ditetapkan jadwal pelaksanaan proyek secara keseluruhan melalui penentuan waktu produk, perubahan material, penetapan biaya produksi, pemilihan parastaf, penentuan waktu produk selesai, kontrol kualitas dari pengiriman produk ke konsumen.

\section{Reverse Engineering}

Reverse Engineering adalah proses tingkat empat dalam perkembanga teknik data untuk menyuport effisiensi yang digunakan dari capital resourse dan untuk menaikkan productivity. Reverse engineering memerlukan data yang akurat untuk pengembangan jangka waktu panjang dan alat bantu untuk kapabilitas teknik dimana ini merupakan yang paling utama pada reverse Enginerring. Sukses pada reverse engginering umumnya diukur dengan kembalinya jumlah modal dalam waktu tertentu. Demikian pula sukses $\mathrm{RE}$ juga diukur dari efektifitas menyeluruh dari objektif jangka panjang dan pendek.

Dalam reverse enginerring ada beberapa hal-hal penting yang harus diperhatikan :

1. Reverse enginerring sebuah series line production.

2. Reverse enginerring adalah menghasilkan sebuah product atau komponen dengan efisiensi tinggi atau kualitas dengan biaya yang rendah.

3. Reverse enginerring mengidentifikasikan kelemahan sistem dalam berbagai usaha.

4. Dokumen yang baru, dipakai untuk menyokong peralatan dan sistem dokumen peralatan pemeliharaan adalah hal yang snagt penting pada pembuatan produk dari Reverse Enginerring.

HASIL DAN PEMBAHASAN

Phase 1. Product Planing
Pemilihan Konsep Hasil HOQ

Pengembangan Produk "Tang Jepit"

Berdasarkan dari susunan House of Quality (HOQ) yang dikembangkan pada pengembangan produk Tang Jepit adalah sebagai berikut :

Tabel 1. Tabulasi proporsi pengembangan produk yang diinginkan.

\begin{tabular}{|c|l|c|}
\hline No. & \multicolumn{1}{|c|}{ PKK } & $\begin{array}{c}\text { Hasil Bobot } \\
\text { PKK (\%) }\end{array}$ \\
\hline 1. & PKK 5: 2 in 1 & $29,69 \%$ \\
\hline 2. & PKK 3: Harga Sesuai & $22,09 \%$ \\
\hline 3. & $\begin{array}{l}\text { PKK 1: Berat kurang } \\
\text { dari 0,5 Kg }\end{array}$ & $15,06 \%$ \\
\hline 4. & $\begin{array}{l}\text { PKK 2: Panjang } \\
\text { kurang dari 25 Cm }\end{array}$ & $14,5 \%$ \\
\hline 5. & $\begin{array}{l}\text { PKK 6: Ketahanan } \\
\text { terhadap slip }\end{array}$ & $10,15 \%$ \\
\hline 6 & $\begin{array}{l}\text { PKK 6: Hardness } \\
\text { dan Tahan Korosi }\end{array}$ & $8,51 \%$ \\
\hline
\end{tabular}

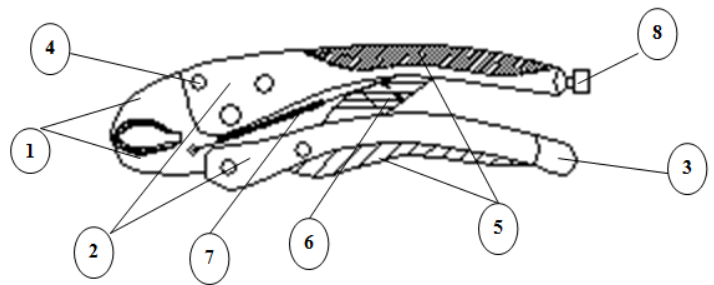

Gambar 4. Sket Hasil HOQ Pengembangan Produk "Tang Jepit"

\section{Keterangan}

1. Komponen / part 1. Mulut Penjepit

2. Komponen / part 2. Handle Atas dan Bawah

3. Komponen / part 3. Tangkai Pelepas Kuncian

4. Komponen / part 6. Keling

5. Komponen / part 8. Karet Pelapis Handle

6. Komponen / part 4. Batang Penghubung Handle Atas dengan Handle Bawah

7. Komponen / part 7. Pegas

8. Komponen / part 5. Baut Pengunci 


\section{Phase 2. Part Deployment}

Secara lebih rinci dapat disimpulkan adapun Komponen-komponen yang dikembangkan sebagai berikut :

1. Mulut penjepit dimana pada sebuah Tang Jepit terdapat dua tipe mulut, yaitu bentuk kurva dan benk lurus ( 2 in 1) sehingga lebih effisien dalam segi penggunaannya.

2. Handle bagian atas dan bawah dilapisi karet dengan kekasaran tertentu untuk mencegah terjadinya slip pada saat penjepitan benda kerja.

3. Panjang Tang Jepit pada kondisi awa sepanjang $25 \mathrm{~cm}$ dikembangkan menjadi $28 \mathrm{~cm}$ diakibatkan bertambah panjangnya mulut penjepit.

4. Barat total Tang Jepit kurang dari $0,5 \mathrm{~kg}$.

\section{Phase 3. Proses Planing.}

Analisa Gaya dan Momen yang terjadi Tang Jepit. Pada perhitungan ini diasumsikan gaya yang diberikan pada handle pada Tang Jepit adalah $P=50 \mathrm{~N}$.

$\sqrt{ }$ Analisa titik F

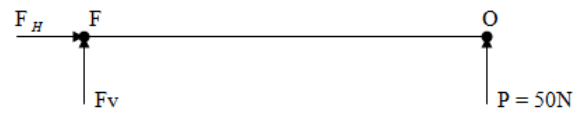

$\begin{array}{cc}* \sum F x=0 & * \sum \mathrm{Fy}=0 \\ F_{H}=0 & \mathrm{P}=\mathrm{Fv} \\ & \mathrm{Fv}=50 \mathrm{~N}\end{array}$

Analisa titik E

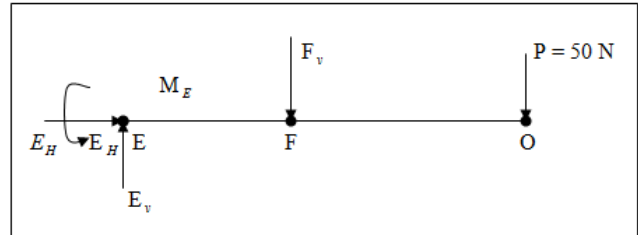

Jarak Titik $O E=0,15 \mathrm{~m} ; \mathrm{FE}=0,015 \mathrm{~m}$

* $\sum F x=0 \quad *$ Arah cw (+)

$E_{H}=0 \quad \sum \mathrm{M}_{\mathrm{E}}=0$

* $\sum F y=0 \quad \mathrm{P}(0.15 \mathrm{~m})+\mathrm{F}_{\mathrm{v}}(0.015 \mathrm{~m})-M_{E}=0$

$P+F_{v}-E_{y}=0 \quad 7.5 \mathrm{~N}+0.75 \mathrm{~N}-\mathrm{M}_{\mathrm{E}}=0$

$50 N+50 N-E_{v}=0 \quad \mathrm{M}_{\mathrm{E}}=8.25 \mathrm{Nm}$

$E_{\mathrm{v}}=100 \mathrm{~N}$

$\checkmark$ Analisa tititk $\mathrm{B}=\mathrm{C}$

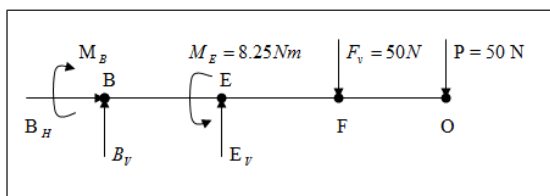

$$
\begin{aligned}
& \text { Jarak Titik } O B=0,165 \mathrm{~m} ; \mathrm{FB}=0,03 \mathrm{~m} ; \mathrm{EB}=0,015 \mathrm{~m} \\
& * \sum F_{x}=0 \quad * \text { Arah cw (+) } \\
& \mathrm{B}_{\mathrm{H}}=0 \quad \sum \mathrm{M}_{\mathrm{B}}=0 \\
& \mathrm{~B}_{\mathrm{v}}=0 \quad \mathrm{M}_{\mathrm{B}}=0
\end{aligned}
$$

$\checkmark$ Analisa tititk D

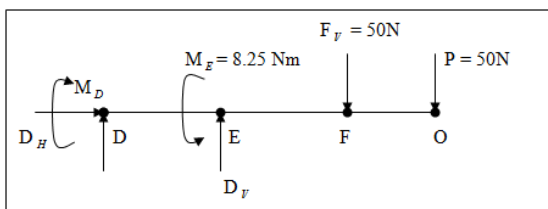

$$
\begin{array}{ll}
\text { Jarak Titik OD }=0,18 \mathrm{~m} ; \mathrm{FD}=0,045 \mathrm{~m} ; \mathrm{ED}=0,015 \mathrm{~m} \\
\begin{array}{ll}
* F x=0 & * \text { Arah cw }(+) \\
\mathrm{D}_{\mathrm{H}}=0 & \sum \mathrm{M}_{\mathrm{D}}=0 \\
* \sum F y=0 & \mathrm{P}(0,18 \mathrm{~m})+\mathrm{F}_{\mathrm{V}}(0,045 \mathrm{~m})-E v(8,25 m)-M_{E}+M_{D}=0 \\
\mathrm{P}+\mathrm{F}_{\mathrm{V}}-E_{V}-D_{V}=0 & (9)+(2,25)-(8,25)-(8,25)+\mathrm{M}_{\mathrm{D}}=0 \\
50 \mathrm{~N}+50 \mathrm{~N}-100 \mathrm{~N}-\mathrm{D}_{\mathrm{V}}=0 & \mathrm{M}_{\mathrm{D}}=5,25 \mathrm{Nm} \\
\mathrm{D}_{\mathrm{V}}=0 &
\end{array}
\end{array}
$$


$\sqrt{ }$ Analisa tititk A

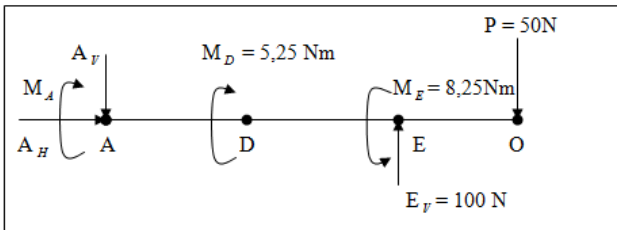

Jarak Titik $O A=0,28 \mathrm{~m} ; \mathrm{EA}=0,13 \mathrm{~m} ; \mathrm{DA}=0,1 \mathrm{~m}$

$* \sum F x=0$

$\mathrm{A}_{\mathrm{H}}=0$

* $\sum F y=0$

$\mathrm{A}_{\mathrm{V}}+P-E_{V}=0$

$\mathrm{A}_{\mathrm{V}}+50 N-100 N=0$

$\mathrm{A}_{\mathrm{V}}=50 \mathrm{~N}$

Maka dari perhitungan diatas dapat dibuat bidang momen sebagai berikut :

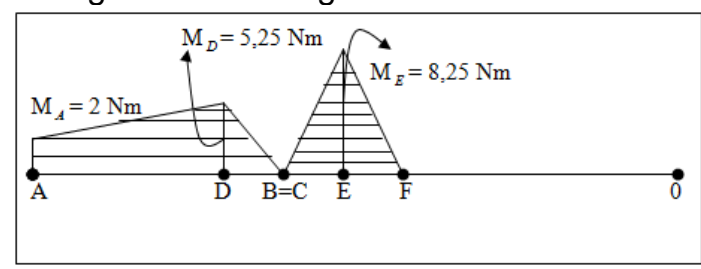

Jadi dari Bidang momen yang tergambar diatas bisa ditarik suatu kesimpulan :

1. Momen yang terbesar terjadi pada titik $\mathrm{E}$ ( keling $\mathrm{E}$ ) sebesar $\mathrm{M}_{E}=$ $8,25 \mathrm{Nm}$.

2. Momen terbesar kedua terjadi pada titik $\mathrm{D}$ ( keling $\mathrm{D}$ ) sebesar $\mathrm{M}_{D}=$ $5,25 \mathrm{Nm}$

3. Momen yang terajadi di titik A sebesar $M_{A}=2 \mathrm{Nm}$. Maka agar benda kerja tidak bergerak dari tempat yang diinginkan atau dikatakan aman apabila gaya tekan $(P)$ yang diberikan harus lebih besar dari $\mathrm{A}_{V}$ dikalikan koefisien geseknya atau dapat dituliskan $A_{V} \cdot \mu \leq \mathrm{P}$

Analisa Kekuatan Paku Keling

Pada perhitungan kekuatan paku keling yang akan dilakukan dihitung berdasarkan keling yang menerima gaya dan momen yang paling besar berdasarkan pada perhitungan sebelumnya.

$\checkmark$ Analisa Keling $F$ keling

a. Tegangan tarik pada batang paku

$$
\begin{aligned}
\sigma_{t} & =\frac{4 F}{\pi \mathrm{d}^{2}} \\
& =\frac{4 \cdot(50 \mathrm{~N})}{3,14 .(4 \mathrm{~mm})} \\
& =15,92 \mathrm{Nmm}
\end{aligned}
$$

b. Tegangan tekan pada kepala keling

$$
\begin{aligned}
\sigma_{e} & =\frac{4 F}{\pi\left(D^{2}-d^{2}\right)} \\
& =\frac{4 \cdot(50 \mathrm{~N})}{3,14 \cdot(8 \mathrm{~mm}-4 \mathrm{~mm})} \\
& =15,92 \mathrm{Nmm}
\end{aligned}
$$
keling

c. Tegangan geser pada kepala paku

$$
\begin{aligned}
\tau_{S} & =\frac{F}{\pi \cdot d \cdot h o} \\
& =\frac{50 \mathrm{~N}}{3,14 \cdot(4 \mathrm{~mm}) \cdot(2,5 \mathrm{~mm})} \\
& =1,59 \mathrm{Nmm}
\end{aligned}
$$

dimana $\tau_{s}=$ tegangan geser yang diijinkan dari bahan paku keling. Sehingga Diameter kepala paku keling dapat ditentukan berdasarkan hasil perhitungan $\tau_{t}$ dan $\sigma_{e}$ yaitu :

$$
\begin{aligned}
D & =\left[\sqrt{\frac{\left|\sigma_{t}\right|}{\left|\sigma_{e}\right|}+1}\right] \mathrm{d} \\
& =\left[\sqrt{\frac{15,92 N m m}{15,92 N m m}+1}\right] \mathrm{d} \\
& =1,4 \mathrm{~d}
\end{aligned}
$$

sedangkan tinggi kepala paku keling dapat ditentukan berdasarkan $\sigma_{t}$ dan $\tau_{s}$ yaitu : 


$$
\begin{aligned}
h o & =0,25 \mathrm{~d} \frac{\left|\sigma_{\mathrm{t}}\right|}{\left|\tau_{\mathrm{S}}\right|} \\
& =0,25 \mathrm{~d} \frac{15,92 \mathrm{Nmm}}{1,59 \mathrm{Nmm}} \\
& =2,5 \mathrm{~d}
\end{aligned}
$$

Sehingga untuk menjaga agar perancangan tetap aman atau memenuhi persyaratan prancangan maka diambil

$$
\begin{aligned}
& D=1,75 d \\
& h=2,8 d
\end{aligned}
$$

\section{$\checkmark$ Analisa Keling E} keling

a. Tegangan tarik pada batang paku

$$
\begin{aligned}
\sigma_{t} & =\frac{4 F}{\pi \mathrm{d}^{2}} \\
& =\frac{4 .(100 \mathrm{~N})}{3,14 .(4 m m)} \\
& =31,85 \mathrm{Nmm}
\end{aligned}
$$

b. Tegangan tekan pada kepala keling

$$
\begin{aligned}
\sigma_{e} & =\frac{4 F}{\pi\left(D^{2}-d^{2}\right)} \\
& =\frac{4 \cdot(100 \mathrm{~N})}{3,14 \cdot(8 \mathrm{~mm}-4 \mathrm{~mm})} \\
& =31,84 \mathrm{Nmm}
\end{aligned}
$$
keling

c. Tegangan geser pada kepala paku

$$
\begin{aligned}
\tau_{s} & =\frac{F}{\pi \cdot d \cdot h o} \\
& =\frac{100 \mathrm{~N}}{3,14 \cdot(4 m m) \cdot(2,5 \mathrm{~mm})} \\
& =3,2 \mathrm{Nmm}
\end{aligned}
$$

dimana $\tau_{s}=$ tegangan geser yang diijinkan dari bahan paku keling. Sehingga Diameter kepala paku keling dapat ditentukan berdasarkan hasil perhitungan $\tau_{t}$ dan $\sigma_{e}$ yaitu :

$$
\begin{aligned}
D & =\left[\sqrt{\frac{\left|\sigma_{t}\right|}{\left|\sigma_{e}\right|}+1}\right] \mathrm{d} \\
& =\left[\sqrt{\frac{31,85 N m m}{31,84 N m m}+1}\right] \mathrm{d} \\
& =1,4 \mathrm{~d}
\end{aligned}
$$

sedangkan tinggi kepala paku keling dapat ditentukan berdasarkan $\sigma_{t}$ dan $\tau_{s}$ yaitu :

$$
\begin{aligned}
h o & =0,25 \mathrm{~d} \frac{\left|\sigma_{\mathrm{t}}\right|}{\left|\tau_{\mathrm{s}}\right|} \\
& =0,25 \mathrm{~d} \frac{31,85 \mathrm{Nmm}}{3,2 \mathrm{Nmm}} \\
& =2,5 \mathrm{~d}
\end{aligned}
$$

Sehingga untuk menjaga agar perancangan tetap aman atau memenuhi persyaratan prancangan maka diambil

$$
\begin{aligned}
& D=1,75 d \\
& h=2,85 d
\end{aligned}
$$

\section{Phase 4. Production Planing}

Dari konsep yang telah dibuat dan desain yang dihasilkan dapat diketahui bahwa kebanyakan dari komponen yang dipilih adalah menggunakan besi cor. Untuk itu proses produksi yang dipilih menggunakan metode Pengecoran (casting), Penempaan (forging), Penekanan (ekstrusi). Disamping itu untuk bagian yang tidak terbuat dari metal akan dilakukan proses yang sesuai. Proses-proses yang dilakukan adalah sebagai berikut:

\section{Komponen / part 1. Mulut Penjepit}

Proses pengerjaan pertama dikerjakan dengan proses pengecoran dengan bahan besi cor, Selanjutnya dilakukan proses pemesinan unruk membuat gigi penjepit berbentuk gerigi yang berfungsi untuk mencekam benda yang akan dijepit. Selanjutnya pelapisan galvanis untuk mencegah karat/korosi. 
Komponen / part 2. Handle Atas dan Bawah

Proses pengerjaan ini dikerjakan dengan proses forging dengan bahan besi cor, selanjutnya dilakukan pengecekan dimensi. Terakhir dilakukan proses pelapisan galvanis untuk tahan karat/korosi.

Komponen / part 3. Tangkai Pelepas Kuncian

Proses pengerjaan ini dikerjakan dengan proses forging dengan besi cor, selanjutnya pengecekan dimensi. Terakhir dilakukan proses pelapisan galvanis untuk tahan korosi/karat.

Komponen / part 4. Batang Penghubung Handle Atas dengan Handle Bawah

Proses pengerjaan ini dikerjakan dengan proses ekstrusi dengan bahan besi cor. Selanjutnya dilakukan pengecekan dimensi. Pelapisan galvanis dilakukan pada proses terakhir untuk mencegah korosi/karat.

\section{Komponen / part 5. Baut Pengunci}

Dilakukan dengan proses pemesinan yaitu membuat ulir luar dengan bahan besi cor untuk yang fungsinya untuk menjaga lebar mulut rahang penjepit agar tidak berubah dari tempat yang diinginkan. Terakhir dilakukan pelapisan galvanis untuk mencegah karat/korosi.

Komponen / part 6. Keling

Material ini hanya diorder sesuai dengan dimensi dam material yang dibutuhkan.

\section{Komponen / part 7. Pegas}

Material ini diorder sesuai dengan dimensi yang dibutuhkan.

Komponen / part 8. Karet Pelapis Handle

Material ini diorder sesuai dengan dimensi dan jenis karet yang diinginkan.

\section{SIMPULAN DAN SARAN}

Dari hasil penelitian yang dihasilkan maka dapat disimpulkan sebgai berikut:
1. Pada phase 1

\begin{tabular}{|c|l|c|}
\hline No. & \multicolumn{1}{|c|}{ PKK } & $\begin{array}{c}\text { Hasil Bobot } \\
\text { PKK (\%) }\end{array}$ \\
\hline 1. & PKK 5: 2 in 1 & $29,69 \%$ \\
\hline 2. & PKK 3: Harga Sesuai & $22,09 \%$ \\
\hline 3. & $\begin{array}{l}\text { PKK 1: Berat kurang } \\
\text { dari 0,5 Kg }\end{array}$ & $15,06 \%$ \\
\hline 4. & $\begin{array}{l}\text { PKK 2: Panjang } \\
\text { kurang dari 25 Cm }\end{array}$ & $14,5 \%$ \\
\hline 5. & $\begin{array}{l}\text { PKK 6: Ketahanan } \\
\text { terhadap slip }\end{array}$ & $10,15 \%$ \\
\hline 6 & $\begin{array}{l}\text { PKK 6: Hardness } \\
\text { dan Tahan Korosi }\end{array}$ & $8,51 \%$ \\
\hline
\end{tabular}

2. Pada phase 2.

Komponen-komponen yang dikembangkan dealam pengembangan produk tang jepit:

1. Mulut penjepit dimana pada sebuah Tang Jepit terdapat dua tipe mulut, yaitu bentuk kurva dan benk lurus ( 2 in 1) sehingga lebih effisien dalam segi penggunaannya.

2. Handle bagian atas dan bawah dilapisi karet dengan kekasaran tertentu untuk mencegah terjadinya slip pada saat penjepitan benda kerja.

3. Panjang Tang Jepit pada kondisi awa sepanjang $25 \mathrm{~cm}$ dikembangkan menjadi $28 \mathrm{~cm}$ diakibatkan bertambah panjangnya mulut penjepit.

4. Barat total Tang Jepit kurang dari $0,5 \mathrm{~kg}$.

3. Pada phase 3 .

1. Momen yang terbesar terjadi pada titik $\mathrm{E}$ ( keling $\mathrm{E}$ ) sebesar $\mathrm{M}_{E}=$ $8,25 \mathrm{Nm}$.

2. Momen terbesar kedua terjadi pada titik $\mathrm{D}$ ( keling $\mathrm{D}$ ) sebesar $\mathrm{M}_{D}=$ $5,25 \mathrm{Nm}$

3. Momen yang terajadi di titik A sebesar $M_{A}=2 \mathrm{Nm}$. Maka agar benda kerja tidak bergerak dari tempat yang diinginkan atau dikatakan aman apabila gaya tekan $(P)$ yang diberikan harus lebih besar 
dari $\mathrm{A}_{V}$ dikalikan koefisien geseknya atau dapat dituliskan $A_{V} \cdot \mu \leq \mathrm{P}$

4. Untuk menjaga agar perancangan tetap aman atau memenuhi persyaratan prancangan maka diambil diameter paku keling $\mathrm{D}=$ $1,75 \mathrm{~d}$, dengan tinggi $\mathrm{h}=2,85 \mathrm{~d}$

4. Pada phase 4.

1. Komponen / part 1. Mulut Penjepit Proses pengerjaan dikerjakan dengan proses pengecoran dengan bahan besi cor, Selanjutnya dilakukan proses pemesinan unruk membuat gigi penjepit berbentuk gerigi yang berfungsi untuk mencekam benda yang akan dijepit. Selanjutnya pelapisan galvanis untuk mencegah karat/korosi.

2. Komponen / part 2. Handle Atas dan Bawah

Proses pengerjaan ini dikerjakan dengan proses forging dengan bahan besi cor, Selenjutnya dilakukan proses pelapisan galvanis untuk tahan karat/korosi.

3. Komponen / part 3. Tangkai Pelepas Kuncian

Proses pengerjaan ini dikerjakan dengan proses forging dengan besi cor, selanjutnya dilakukan proses pelapisan galvanis untuk tahan korosi/karat.

4. Komponen / part 4. Batang Penghubung Handle Atas dengan Handle Bawah

Proses pengerjaan ini dikerjakan dengan proses ekstrusi dengan bahan besi cor. Selanjutnya dilakukan pelapisan galvanis pada proses terakhir untuk mencegah korosi/karat.

5. Komponen / part 5. Baut Pengunci Dilakukan dengan proses pemesinan yaitu membuat ulir luar dengan bahan besi cor untuk yang fungsinya untuk menjaga lebar mulut rahang penjepit agar tidak berubah dari tempat yang diinginkan. Terakhir dilakukan pelapisan galvanis untuk mencegah karat/korosi.
6. Komponen / part 6. Keling Material ini hanya diorder sesuai dengan dimensi dam material yang dibutuhkan.

7. Komponen / part 7. Pegas

Material ini diorder sesuai dengan dimensi yang dibutuhkan.

8. Komponen / part 8. Karet Pelapis Handle

Material ini diorder sesuai dengan dimensi dan jenis karet yang diinginkan.

Menyadari banyak kekurangan dalam hasil penelitian ini maka disarankan Dalam proses manufaktur, hal yang penting untuk dipertimbangkan adalah biaya, yaitu apakah suatu rancangan yang telah dibuat bisa dimanufaktur atau tidak. Setelah itu dicoba diusahakan agar dapat menurunkan biaya pada proses manufaktur. Usaha ini diusahakan dengan cara standarisasi komponen-komponen dan material. Menurunkan biaya proses produksi dan perakitan. Pemilihan proses dan perakitan dapat dilihat dengan melihat fungsi dari komponen dan alat produksi.

\section{DAFTAR PUSTAKA}

Dr. Ing. Ir. I Made Londen Batan, Meng, "Pengembangan Produk", Diktat Kuliah, Surabaya, 2004.

George E. Dieter, "Metalurgi Mekanik“, Edisi Ketiga Jilid 2, Penerbit Erlangga, 1986, Jakarta.

H. Darmawan Harso Koesoemo, "Pengantar Perancangan Teknik (Pengembangan Produk) ", Edisi II, ITB Bandung.

Ir. Sardjono, "Mekanika Teknik Statis Tertentu", Karya Indah Surabaya.

Ir Sunarko, "Mekanika Teknik I" , Diktat Kuliah, Jurusan Teknik Mesin FTI-ITS.

Ir. Zainun Achmad, MSC, "Elemen Mesin I", Penerbit PT Refika Aditama, Cetakan Pertama, 1999.

Rakiman; "Pengembangan Produk Kran Air ", Tugas Pengembangan Produk 1, Surabaya, 2004.

Robert C. Juvinall, "Engineering Consideration Of Stress,Strain and Strength", McGraw-Hill Book Company, New York.

Jurnal Sains dan Teknologi| 183 